\title{
Funções Administrativas ou Práticas? As "Artes do Fazer" Gestão na Escola Mirante
}

\author{
Administrative Functions or Practices? The "Arts of Making" \\ Management at Mirante School
}

\author{
Roberta Alvarenga de Almeida Vargas \\ Mestre em Administração, Universidade Federa do Espirito Santo - Vitória - ES, Brasil. E-mail: roberta.psiufes@gmail.com \\ Gelson Silva Junquilho \\ Professor do Programa de Pós-Graduação na Unversidade Federal do Espirito Santo - Vitória - ES, Brasil. \\ E-mail: gelsonufes@gmail.com
}

\section{Resumo}

O objetivo deste artigo é ampliar a compreensão do exercício da gestão como fenômeno coletivo, resultante de práticas construídas pelos sujeitos organizacionais. O fio condutor foi a conceituação de Certeau (2009) sobre a vida cotidiana, locus onde sujeitos sociais desenvolvem "artes do fazer", por meio de suas práticas. O estudo empírico foi realizado em uma escola pública de ensino fundamental, neste artigo, denominada como Mirante, componente do sistema de educação básica do município de Vitória (ES). A estratégia metodológica foi baseada no método etnográfico, desenvolvida por meio de observação direta, complementada por entrevistas e documentos formais. A pesquisa mostra que as "funções administrativas" (FAYOL, 1970) são (re)construídas socialmente, apropriadas que são por meio de práticas, resultantes das ações cotidianas de sujeitos praticantes no seio da escola. Os resultados apontam a complexidade das "artes do fazer" gestão, fenômeno este que é coletivo e não exclusivo da ação de um gestor.

Palavras-chave: Gestão e Práticas Sociais. Cotidiano. Gestão Escolar. Diretor Escolar.

\section{Abstract}

This article aims at broadening the view of management as a collective phenomenon, resulting from practices constructed by organizational subjects. Our guideline was Certeau's (2009) conception of everyday life, locus where social subjects develop the "arts of making" through practice. This empirical study was carried out at a public elementary school, referred to in this article as Mirante school. This school is part of the elementary education system in the City of Vitória, ES, Brazil. Methodological strategy was based on ethnographic approach, carried out through direct observation complemented by interviews and official documents. The investigation shows that the "administrative functions" (FAYOL, 1970) are socially and appropriately (re)constructed through practices resulting from everyday actions by the subjects in the heart of the school. The results point at the complexity of the "arts of making" management, a phenomenon that is collective and not exclusively based on the actions of a manager.

Key words: Management and Social Practices. Everyday Life. School Management. School Principal. 


\section{INTRODUÇÃo}

No atual cenário dos Estudos Organizacionais brasileiros, observa-se uma predominância de abordagens sociológicas da gestão voltadas às generalizações e definições de modelos. Tais trabalhos, por não considerarem as diversas atividades humanas desempenhadas no cotidiano das organizações, com todo seu dinamismo e sua complexidade, têm produzido investigações descoladas da realidade vivida nesses espaços, mostrando-se, portanto, insuficientes para compreender as práticas de gestão (SANTOS; ALCADIPANI, 2010). Nesse sentido, Certeau (2009), há muito, constatou um distanciamento entre os tradicionais instrumentos teórico-metodológicos de investigação utilizados no meio acadêmico e a riqueza inventiva presente nas "práticas ordinárias". Ao longo de sua obra, o autor discorreu sobre uma "teoria das práticas", na qual valoriza o vivido, o ordinário e o efêmero em detrimento de uma analítica da certeza científica.

A partir desse entendimento, este artigo tem por objetivo contribuir para a superação de estudos que versam sobre gestão, a partir da ação protagonista dos gestores (FAYOL, 1970; MINTZBERG, 1973) pela proposição da gestão como resultante das "artes do fazer" de distintos atores (CERTEAU, 2009), dentre eles os gestores, nos cotidianos organizacionais. Para tanto, o cotidiano, em toda a sua complexidade de relações sociais nas organizações, por meio de práticas construídas e tecidas pelos seus sujeitos, é eleito como dimensão fundamental de análise das "artes do fazer" gestão. De maneira mais específica, pretende-se retratar como se configura o fenômeno da gestão, no cotidiano de uma escola pública, tomando-se como base alguns conceitos apresentados por Certeau (2009).

Tal abordagem contribui para uma compreensão distinta de estudos clássicos na literatura internacional (BARNARD, 1938; DALTON, 1959; KOTTER, 1982; MINTZBERG, 1973, 1990) que trouxeram uma crítica importante à definição de gestão apregoada por Fayol (1970), por intermédio das "funções administrativas". Esses estudos foram fundamentais, pois problematizaram a gestão para além de um receituário pragmático a ser aplicado pelos gestores para o alcance de resultados. Entretanto, ainda que tenham apontado perspectivas distintas para a compreensão da gestão como fenômeno processual, aqueles autores elege- ram sempre o gestor como unidade de análise, ora destacando características do trabalho gerencial, ora a própria ação gerencial de forma isolada e restrita ao microcosmo organizacional.

Logo, o foco dessas análises é aquilo que os executivos fazem e como utilizam seu tempo. Michael Reed $(1984,1989)$ permitiu que se identificassem as limitações daqueles autores no tocante ao conceito de gestão ao elaborar a ideia da "gestão com prática social". Em sua abordagem é proposta a análise da gestão a partir da integração entre os níveis institucional, organizacional e comportamental que contempla, ao mesmo tempo, tanto a ação gerencial, quanto a dinâmica da organização e o contexto macroestrutural. Essa proposta configura-se como uma alternativa que contempla não apenas a gestão como processo, mas também como resultante de práticas sociais. Mais recentemente, o estudo das "práticas" nas organizações foi também explorado por Schatzki $(2005,2006)$. Por essa concepção, o citado autor busca a compreensão da gestão de um modo mais aproximado a "como ela acontece", ou seja, reforça a necessidade de aproximações à realidade organizacional cotidiana para contemplar sua dinâmica.

No Brasil, diversos autores discorreram acerca das práticas gerenciais, ressaltando a complexidade do fenômeno da gestão à luz da "gestão como prática social" (REED, 1984; 1989), dentre os quais, Marra e Melo (2005); Ésther e Melo (2006); Paiva et al. (2007); Garcia (2003) entre outros. No entanto, percebe-se que esses estudos, mesmo utilizando-se da abordagem da prática social, comumente têm limitado suas análises à prática do gestor, ou seja, enfatizam a ação gerencial.

Neste artigo, a opção por Certeau (2009) permite não só avançar nos estudos que possam tratar a gestão para além da ação gerencial de forma isolada, como também aprofundar a proposta de inserção da prática social, defendida por Reed $(1984,1989)$ e Schatzki $(2005,2006)$. Entende-se que a abordagem de Certeau (2009) tem muito a contribuir nessa caminhada, já que o foco de análise não é a ação gerencial em si como algo isolado e sim, as práticas sociais daí emergentes. Porém, não se trata só de descrever práticas, mas sim realçar como elas são operadas pelos sujeitos sociais, cotidianamente, nas organizações onde se constroem os processos de gestão, neles inseridos não só o gestor, mas distintos sujeitos praticantes que desenvolvem 
"artes do fazer" que configuram tessituras complexas daqueles mesmos processos.

Para ilustrar essa problematização serão aqui apresentados fragmentos de um estudo realizado em uma escola pública de ensino fundamental do município de Vitória (ES), localizada em comunidade que carrega uma história de luta e mobilização por melhores condições de vida. O problema de pesquisa foi assim definido: como se caracteriza o cotidiano da gestão em uma escola de ensino fundamental no município de Vitória?

Como orientação metodológica, buscou-se inspiração nas pesquisas "nos/dos/com" os cotidianos (ALVES; GARCIA, 2002; FERRAÇO, 2007; GARCIA, 2003), as quais, também ancoradas nas ideias de Certeau (2009), têm buscado alternativas metodológicas para tentar explorar a diversidade e a complexidade das práticas sociais no campo dos estudos educacionais. O artigo apresenta as contribuições teóricas da gestão como prática, a ideia das "artes do fazer" gestão, o percurso metodológico da pesquisa de campo, a análise dos resultados e as tessituras finais.

\section{As Contribuições de Certeau para o Estudo das "Artes do Fazer" Gestão}

A problematização dos conceitos de gestão preconizados por Taylor (1960) e Fayol (1970) será aqui efetuada, a partir da abordagem da prática social proposta por Reed (1989), bem como pelas contribuições do pensador francês Michel de Certeau (2008; 2009) que permitem pensar a gestão como reflexo da ação cotidiana dos sujeitos organizacionais ou, dito de outro modo, das suas "artes do fazer".

\subsection{Gestão e Ação Gerencial: o lugar das práticas}

A partir das definições pioneiras de Taylor (1960) e Fayol (1970), principalmente deste último, a ideia de gestão como ferramenta para alcance de resultados organizacionais passou a ser universalizada. As denominadas "funções administrativas" fayolinas - planejar, controlar, comandar, organizar e avaliar -, desde então, são sinônimos do ato de administrar, fenômeno esse proposto por aquele autor, como de responsabilidade de um ocupante de cargo de gestão.

Diversos estudiosos, clássicos na literatura internacional, passaram então a tratar gestão a partir do foco na ação ou trabalho gerencial, dentre eles: Barnard (1938); Homans (1950); Carlson (1951); March e Simon (1958); Dalton (1959); Collins e Moore (1970); Simon (1970); Mintzberg (1973); Stewart (1976, 1997); Kotter (1982); Cyert e March (1996). O fio condutor que marca esses estudos é a figura do gerente, com destaque para o que se caracteriza o seu trabalho, bem como suas ações.

Esses estudos agregaram conhecimentos à temática da gestão ao problematizarem o caráter limitado das "funções administrativas", suas fragilidades, imprecisões e generalizações, quando confrontadas no mundo empírico, principalmente no tocante à ação $e$ trabalho gerenciais. Um dos autores de grande repercussão nessa abordagem, Mintzberg $(1973,1990)$ constatou que o ato de gerir é uma atividade que se distancia daquilo prescrito por Fayol (1970). Isso porque suas descobertas o permitiram escrever que o trabalho gerencial se efetiva em um plano de muitas incertezas, onde impera a complexidade e distintas fontes e fluxos de informações para a tomada de decisões. A intuição também é um atributo essencial para o alcance de resultados. Esse cenário caracteriza uma diversidade de práticas que, dificilmente, aderem à racionalidade prescritiva das funções administrativas.

Outra contribuição importante dos trabalhos de Mintzberg $(1973 ; 1990)$ é que os atos de planejar, bem como de formatar e executar estratégias não se efetivam unicamente por meio de um sistema formalizado, mas sim mediados pela informalidade, pela negociação, por especulações. Também Stewart (1997) problematiza a generalização do conceito de gestão de Fayol (1970) e, inclusive, acentua que ser gerente e, consequentemente exercer o "management", pressupõe a responsabilidade por alcance de resultados organizacionais que nunca se efetiva sem a interveniência de outras pessoas. Já Whitley (1989) defende que o exercício da gestão depende de ações coletivas, ou seja, da soma de esforços coordenados de diversos atores sociais em determinadas realidades organizacionais.

Logo, fica evidente que a gestão é um processo interdependente, contextual, coletivo, mutável e de di- 
fícil padronização e consequente generalização. Assim, não é possível serem abstraídas questões inerentes ao tempo, ao espaço e as contextualizações específicas, a cada processo (WHITLEY, 1989). Como se vê, a literatura clássica apresentada aqui sobre o trabalho gerencial enfatiza o que o gerente faz e como pode se tornar mais eficaz. Desse modo, a análise fica circunscrita aos limites organizacionais e enaltece o fenômeno da gestão como que exclusivo da ação gerencial. Isso enfraquece a importância das relações sociais que são construídas pelo conjunto de atores que interferem no cotidiano da gestão como processo coletivo, dinâmico e complexo.

Como uma alternativa a essa limitação é importante ressaltar a contribuição de Michael Reed (1984, 1989) que propõe a ideia da gestão como prática social. Nela, a gestão é tomada como resultante de um conjunto de atividades e mecanismos que se interrelacionam, por meio da ação humana, com vistas à organização e controle de atividades produtivas. Essa proposição pressupõe considerar o ato de gerir como inerente a três planos indissociáveis, a saber: institucional, organizacional e relacional. Ou seja, não se faz gestão descolada de um determinado contexto sócio-histórico em uma dada organização, na qual se estabelecem relações sociais.

Desse modo, a ideia de gestão passa a contemplar dilemas socioculturais que os gestores lidam no cotidiano complexo e dinâmico das organizações, no qual eles interagem com outros sujeitos que com eles constroem práticas provisórias, improvisadas, ou muitas vezes até contraditórias que resultam na gestão. Nessa concepção as organizações passam a ser consideradas como bricolagens de distintos princípios e modos de agir que se articulam de forma parcial (REED, 1989). Daí que a gestão passa a ser considerada como um processo que visa à constante articulação de práticas complexas e diversificadas, sempre vulneráveis à desarticulação e fragmentação.

Consideradas as organizações como palco de práticas sociais, sujeitas a várias estratégias de composição e recomposição, a abordagem praxeológica proporciona uma concepção mais realista e flexível do fenômeno da gestão, bem como da ação dos gerentes. Nela é rejeitada a concepção simplista das organizações como unidades rigidamente estruturadas, subordinadas à realização de funções essenciais impostas pelos imperativos econômicos, técnicos, administrativos ou políticos. É possível ainda, pensar as organizações como embebidas em princípios e lógicas geradoras de contradições estruturais e processuais que se refletem nas práticas de gestão.

A ideia do estudo da gestão por meio das práticas também é sugerida por Schatzki $(2005,2006)$. Sua ideia parte do princípio da necessidade de se compreender as organizações de um modo mais aproximado ao que realmente nelas acontece. Dito de outro modo, a proposição básica é o olhar sobre as dinâmicas organizacionais, por meio de seus cotidianos. Sua abordagem considera a prática social como derivada de ações aparentemente ordinárias de sujeitos sociais nas organizações - como tomar decisões, executar uma tarefa, supervisionar, dentre outras - as quais são estruturadas no espaço e no tempo (SCHATZKI, 2006). Portanto, o sujeito social, ao realizar uma prática, é capaz de compreender as ações que esta prática envolve, bem como suas regras, em conjunto com aspectos teleológicos - meios e fins - e afetivos $e$, ainda, um entendimento geral acerca da natureza do seu próprio fazer.

Assim, a partir da importância do uso das práticas, ressaltadas por Reed (1984, 1989) e Schatzki (2005, 2006), como importantes para a compreensão de fenômenos inerentes à gestão organizacional, são trazidos para este artigo alguns pressupostos teóricos básicos do pensador francês Michel de Certeau (2009). Em grande parte de sua obra, ele traz uma contribuição sobre as análises sociais que envolvem a vida cotidiana e que aqui, particularmente, serão muito úteis para a compreensão de como se opera o processo de gestão na organização estudada, a partir das "artes do fazer" dos sujeitos que praticam cotidianos organizacionais.

\subsection{As Práticas como "Artes do Fazer" na Vida Cotidiana}

As proposições de estudos de fenômenos de gestão ancorados na ideia da prática social de Reed (1989) e Schatzki $(2005$; 2006) são muito caras a este artigo. Mas, com o intuito de ampliar o olhar sobre o cotidiano dessas mesmas práticas, com o foco nas diversas formas de suas operacionalizações pelos sujeitos, recorreu-se aos ensinamentos de Certeau (2009), que, em sua obra, apresenta diversas pistas 
sobre as "artes do fazer" dos sujeitos praticantes do/ no cotidiano.

Em Certeau (2009), o cotidiano apresenta-se como locus importante para a análise de fenômenos sociais, pois é onde as práticas locais - plano microssocial - $e$ os aspectos globais - macrossociais - se entrecruzam em tessituras complexas, dinâmicas e singulares, por meio de relações sociais. Nesse sentido, o cotidiano não se limita a algo que implica em simplesmente rotina e repetição (OLIVEIRA, 2008). Ao contrário, o cotidiano é tratado como totalidade complexa (MORIN, 1996), na qual estão presentes e enredados as diferentes dimensões da vida social $e$ os modos como os praticantes da vida cotidiana (CERTEAU, 2009) atuam, sempre de modo singular e único.

É no cotidiano que se materializam as práticas sociais, concebidas estas últimas por Certeau (2009), como distintas, diversas e singulares maneiras, artes de fazer ou estilos de ação, atos que acontecem sempre na relação com o outro, isto é, relações

[...] pelas quais usuários se reapropriam do espaço organizado pelas técnicas da produção sociocultural. Pode-se supor que essas operações multiformes e fragmentárias, relativas a ocasiões e a detalhes, insinuadas e escondidas nos aparelhos das quais elas são os modos de usar, $e$, portanto, desprovidas de ideologias $e$ instituições próprias, obedecem a regras. [...] Essas práticas colocam em jogo uma ratio "popular", uma maneira de pensar investida numa maneira de agir, uma arte de combinar indissociável de uma arte de utilizar. (CERTEAU, 2009, p. 41)

Nessa última citação, observa-se que a percepção de Certeau (2009) sobre as práticas sociais é marcada por um tom otimista, apostando na inteligência e na inventividade do homem comum, o praticante do cotidiano, a quem dedica seu trabalho: "Este ensaio é dedicado ao homem ordinário. Herói comum. Personagem disseminada" (CERTEAU, 2009, p. 55). É com esse respeito para com o outro que o autor, diferentemente de Heller (2008), busca inverter o postulado usual de interpretação das práticas culturais como passivas. Muito pelo contrário, no seu entendimento, é na inventividade humana que se esconde um emaranhado de astúcias silenciosas, sutis e eficazes, pelas quais cada um inventa para si mesmo uma maneira própria de caminhar em meio a um conjunto de imposições.

Assim, na vida cotidiana existem sempre apropriações e ressignificações imprevisíveis, incontroláveis, modificadoras de pretensões previstas na origem, no planejamento e na idealização das coisas. Certeau (2009) apresenta maiores pistas dessa dimensão inventiva do cotidiano ao explorar a problemática dos usos, dos modos de fazer dos usuários, evidenciando as capacidades de desvio e a arte de contornar a racionalidade dos dispositivos estabelecidos pela ordem estatal e comercial. É tomado como pressuposto que os usuários "[...] façam uma bricolagem com e na economia cultural dominante, usando inúmeras e infinitesimais metamorfoses da lei, segundo seus interesses próprios e suas próprias regras" (CERTEAU, 2009, p. 40). Desse modo, Certeau (2009) argumenta que essas leis hegemônicas podem ser subvertidas sem ser rejeitadas ou modificadas diretamente, ou seja, há formas de se escapar do poder sem abandoná-lo totalmente.

Entretanto, é fundamental destacar que o estudo das práticas sociais não significa um regresso aos indivíduos. Diferentemente do atomismo social, cujos pressupostos a análise sociológica é realizada a partir de uma unidade elementar - o indivíduo - na vida cotidiana é

[...] a relação (sempre social) que determina seus termos, e não o inverso, e que cada individualidade é o lugar onde atua uma pluralidade incoerente (e muitas vezes contraditória) de suas determinações relacionais. De outro lado e, sobretudo, a questão tratada se refere a modos de operação ou esquemas de ação e não diretamente ao sujeito que é o seu autor ou veículo. (CERTEAU, 2009, p. 37)

A partir dessas ideias de Certeau (2009) é que se realizou a pesquisa que buscou a compreensão de como se operam "artes do fazer" gestão em uma escola pública, processo no qual a ação do diretor escolar é construída a partir de suas relações com sua comunidade escolar - professores, técnicos pedagógicos e administrativos, alunos, pais -, membros do órgão central do Sistema Municipal de educação, fornecedores, agentes políticos, dentre outros atores. Nesse espaço habitado e vivenciado que é a escola, são exercidas e praticadas as funções administrativas (FAYOL, 1970) inerentes ao cargo de diretor. 
Assim, os sujeitos praticantes da comunidade escolar, aí incluído o diretor, costuram, tecem enfim, normas e condutas instituídas de poder de forma a tornar a gestão da escola exequível ou possível. No cotidiano, o diretor escolar funciona como uma espécie de regulador, o qual, graças a relações de poder nas quais se inserem, consegue um aparente equilíbrio das referências que efetivam modos singulares de exercício das funções administrativas. Dito de outra maneira, a partir dos ensinamentos de Certeau (2009), a busca neste artigo é compreender como são operacionalizadas "artes do fazer" gestão na escola estudada, realçando-se as invenções, as artimanhas, as tramas e interpretações dos seus sujeitos praticantes em relação ao exercício da gestão. Enfim, como diria Duran (2007, p. 117), "[...] suas maneiras de fazer - a pesquisa das práticas - a lógica do cotidiano". Essa busca no campo presume ir ao encontro dos sujeitos praticantes e vivenciar esse cotidiano, para torná-lo visível. No tópico a seguir, serão apresentados os caminhos metodológicos "praticados" na pesquisa que originou este artigo.

\section{Percursos Metodológicos}

Para o estudo das "artes do fazer" gestão em uma escola pública, este artigo foi inspirado, no plano metodológico, por pesquisas realizadas em cotidianos escolares por autores como Alves (2002), Ferraço (2003, 2007) e Oliveira $(2002,2008)$, dentre outros, em busca de alternativas para explorar a diversidade e a complexidade da vida cotidiana. Eles praticam o que denominam ser um necessário "mergulho" no cotidiano estudado pelo pesquisador, o qual visa romper com o distanciamento sujeito-objeto de pesquisa. Nessa perspectiva, os dados não são coletados pelo pesquisador, mas sim construídos a partir de sua interação com o cotidiano, rompendo-se com a ideia de neutralidade científica na pesquisa.

A abordagem escolhida para estudo desse cotidiano foi a de cunho etnográfico (GEERTZ, 1989; CAVEDON, 2003). O mergulho no cotidiano é uma perspectiva que defende uma observação que exige do pesquisador a disposição para interagir com todos os sentidos de uma dada realidade. Assim, não só o sentido da visão é importante, mas também os cheiros, as sutilezas sonoras, os sabores, a expressão corporal, dentre outros "invisíveis", em uma escola (ALVES, 2002). Com o uso dessa abordagem a intenção foi não só ir à escola, mas também habitar esse espaço e dar voz aos sujeitos praticantes de seu cotidiano. Na pesquisa que originou este artigo a base para a "construção" dos dados foi a observação direta. Como ferramentas de apoio, foram também utilizados outros recursos complementares como: conversações com sujeitos praticantes da escola, entrevistas ao diretor $e$ professores e documentos formais da escola.

Assim, a pesquisa que deu origem a este artigo foi realizada em uma escola de ensino fundamental da rede municipal da cidade de Vitória (ES), localizada em um bairro periférico, aqui denominada escola Mirante. Durante o "mergulho no cotidiano" escolar, por meio da observação direta, foram analisadas tanto a estrutura como a dinâmica da unidade de ensino. Assim, participou-se de atividades de rotina, como reuniões administrativas e pedagógicas, conselhos de classe, atendimento a pais, intervalos de recreio, festas e outros eventos promovidos na escola.

Nesse sentido, a vivência no cotidiano escolar foi de cinco meses, de agosto a dezembro de 2010. Nesse período seus diferentes espaços, como corredores; sala dos professores; biblioteca; sala do diretor, da coordenação e dos pedagogos; e pátio de recreação foram habitados por um dos autores deste artigo. Um dos locais mais frequentados foi a sala dos professores, pois aí, onde os educadores tomam um cafezinho e trocam ideias, era concretizada a troca de experiências vividas. Importante ressaltar que a observação foi centrada na figura do diretor escolar, isto é, tomado esse sujeito praticante como foco principal para a concretização da gestão escolar. Logo, nas diversas idas ao campo buscava-se sempre acompanhar as rotinas diárias do diretor da Mirante.

Durante o período da observação, portava-se sempre no bolso um pequeno bloco de anotações, no qual eram registradas palavras-chave, falas ou breves notas que serviram de base para a escrita de um diário de campo. Imediatamente após as visitas a campo, passava-se à redação do diário, nos quais foram narrados, dia após dia, todos os acontecimentos, conversas e sentimentos vivenciados no cotidiano escolar. Os diários foram escritos em meio eletrônico, pelo fato de facilitar o manuseio das informações. 
Durante as vivências no campo, foram realizadas muitas conversações com distintos sujeitos praticantes da comunidade escolar que trouxeram indícios sobre as diversas questões que atravessavam o cotidiano escolar. Tais conversações caracterizaram-se por seu caráter dialógico, livre e aberto, nas quais os sujeitos praticantes podiam manifestar-se como são, sem precisarem sentir-se presos a papéis determinados, conforme defende Sarmento (2000). Foi praticada então, a sugestão de Larossa (2004, p. 160), que ensina a importância de se "[...] abrir os olhos e os ouvidos, falar sobre o que nos acontece, [...] escutar os outros, cultivar a arte do encontro, calar muito".

Ao final do período de pesquisa de campo, quando já se estava mais familiarizado com as relações e dinâmicas da escola Mirante, partiu-se para a realização de algumas entrevistas a determinados sujeitos praticantes. Foram elaborados quatro diferentes roteiros de entrevista semiestruturados: um para o diretor; um para os servidores e magistério; um para os pais e alunos e um para representantes da Secretaria Municipal de Educação. Ao todo, foram quatorze entrevistas, todas gravadas e transcritas, exceto a do diretor que não foi gravada por sua preferência. As entrevistas tiveram uma duração média de 50 minutos cada. Outra fonte importante de informação foram os documentos produzidos na escola, como comunicados em quadro de avisos e relatórios de gestão próprios.

A análise dos dados produzidos por meio de diários de campo, entrevistas e demais fontes foi realizada a partir de uma leitura atenta e reflexiva desse material, objetivando-se destacar os seguintes aspectos: forma da organização escolar - localização, espaço físico, regime de funcionamento, especificidades estruturais, etc. -; aspectos da identidade da escola - a história, os valores, a escola na visão da comunidade escolar, etc. - e aspectos do cotidiano escolar - a relação escola-comunidade, as tomadas de decisão, os conflitos existentes. A apresentação desses dados, a seguir, foi feita a partir de "fragmentos" do cotidiano que confrontam as chamadas funções administrativas (FAYOL, 1970) com o mundo vivido e praticado da gestão na Mirante.

\section{As "Artes de Fazer" Gestão no Cotidiano da Escola Mirante}

\subsection{Breves Notas Sobre Escola Pública De Ensino Básico e sua Gestão no Brasil}

Como afirma Dora (2006), a escola pública de educação básica é uma organização que se constitui como resultado de um movimento dialético de construção e destruição. Assim, ela está envolta em tramas complexas permeadas pelas relações que aí se estabelecem entre o Estado e a sociedade civil em seu cotidiano e pode assumir distintas faces e sentidos, em distintas conjunturas (ROCKWELL; EZPELETA, 2006; ALVES; GARCIA, 2002). Ainda como organização social, a escola pública pode ser tomada como do tipo "pluralística" já que nela são encontradas "[...] três principais características: objetivos múltiplos, poder difuso e processos de trabalhos com base no conhecimento". (DENIS; LANGLEY; ROULEAU, 2007, p. 179-180, tradução nossa)

Tomada a escola pública como lócus de múltiplas e distintas práticas (BASTOS, 2005), a gestão escolar, mesmo quando inserida em uma dada política educacional de Estado, assume, cotidianamente, diversas práticas ou "fazeres" específicos, contextualizados em nível local, dada as relações sociais que aí se estabelecem no seio da comunidade escolar (LÜCK, 2006). Logo, não existe uma escola igual a outra, no plano do seu cotidiano e suas práticas, tanto pedagógicas como administrativas (SARMENTO, 2000). As políticas estatais são guias ou regras gerais orientadoras de sistemas educacionais que nas escolas assumem distintas dinâmicas diferenciadas, pela ação de seus sujeitos (ALVES; GARCIA, 2002; LÜCK, 2007)

Um fator que reforça a especificidades dos cotidianos das escolas públicas no caso do Brasil é a definição, dada pela Constituição de 1988, da educação como democrática, diretriz esta sacramentada pela Lei n. 9.394/96 - Diretrizes e Bases da Educação Nacional (LDB) que definiu a Gestão Democrática no ensino público nacional, nos níveis federal, estadual e municipal. No entendimento de Drabach e Mousquer (2009) esse instrumento legal originou um desenho organizacional de escola autônomo $e$ inspirado na ideia de democratização de seus processos decisórios, calcado em práticas construídas coletivamente, como 
alternativa para superação da centralização burocrática até então reinante nos sistemas educacionais estatais.

Desse modo, a participação na gestão escolar é garantida a todos os sujeitos sociais que compõem as chamadas comunidades escolares - educadores, funcionários administrativos, pais, alunos, representantes comunitários. Portanto, a gestão não está restrita à ação do diretor escolar (LÜCK, 2007). Mais que isso, ainda que seja detentor de autoridade formal para dirigir uma unidade de ensino, o diretor é levado a construir a gestão escolar, cotidianamente, com os demais sujeitos envolvidos no processo da gestão escolar democrática. (GALVÃO; SILVA; SILVA, 2011; PARO, 2010; SOUZA; GOUVEIA, 2010; LÜCK, 2007)

Para se viabilizar, a gestão democrática na escola pública de ensino básico - pela LDB o ensino básico é composto por três modalidades: educação infantil, ensino fundamental e ensino médio - conta com instrumentos tais como: a eleição para o cargo de diretor escolar; os Conselhos de Escola em cada unidade de ensino, instância decisória que define estratégias pedagógicas e administrativas, composta por representantes de pais, alunos, magistério, servidores administrativos, moradores e o diretor escolar como membro nato; os grêmios estudantis para representação política dos alunos; a preconização da autonomia administrativa, financeira e pedagógica da escola.

Assim, a gestão democrática impõe paradoxos às escolas públicas, dadas as dificuldades cotidianas das relações sociais entre a comunidade escolar. As tomadas de decisão se tornam mais complexas e plenas de tensão e conflito de interesses e forças distintos. Por isso, em muitas experiências, são observadas escolas com práticas de gestão centralizadoras, onde o exercício do poder está muito centrado nas mãos de um diretor. Por outro lado, também são notados processos de gestão inovadores e participativos que incentivam a interação da comunidade escolar. Nesses casos, são construídas as escolhas e os projetos de forma coletiva e mais transparente. (LÜCK, 2006; BASTOS, 2005)

A seguir, serão apresentados "fragmentos" da gestão na escola Mirante que ilustram a complexidade da construção cotidiana de práticas sociais ou "artes do fazer" de seus "sujeitos praticantes" (CERTEAU, 2009) que realçam a gestão não só como mero evento de funções administrativas, mas sim como produto e produtora de práticas sociais naquela unidade de ensino.

\subsection{A Caracterização da Escola Mirante}

A escola Mirante pertence ao Sistema Municipal de educação de Vitória (ES) e está localizada em um bairro periférico da cidade, que surgiu de um processo de ocupação por imigrantes que vieram para a capital capixaba, em decorrência do êxodo rural ocasionado pela crise do café (ROCHA, 1998), a partir de meados dos anos 1950. Atualmente, o bairro em questão é reconhecido como um importante ponto de tráfico de drogas na cidade, fato este que se apresenta como um fator que aumenta a complexidade das "artes do fazer" gestão na referida escola.

No tocante ao seu funcionamento, a escola Mirante é uma unidade de ensino fundamental e tem, em média, matriculados 480 alunos. No turno matutino a escola atende alunos das séries finais do ensino fundamental - do $6^{\circ}$ ao $9^{\circ}$ ano. No turno vespertino são atendidos os alunos das séries iniciais - do $2^{\circ}$ ao $5^{\circ}$ ano. São duas turmas para cada ano/série, totalizando oito turmas em cada turno. Já os alunos de $1^{\circ}$ ano da escola estão alocados em um Centro Municipal de Educação Infantil no bairro vizinho, uma vez que a organização do ensino fundamental em nove anos é uma estruturação recente, que passou a ser obrigatória a partir do ano de 2010. Assim, como há limitação de espaço e salas de aula na escola, essas turmas funcionam em outro estabelecimento de maneira independente, mas oficialmente a pertencem.

No seu quadro de pessoal, a escola possui 50 servidores, dos quais vinte e seis professores, quatro coordenadores, quatro pedagogos, três assistentes administrativos e treze auxiliares de serviços gerais, estes últimos terceirizados, que cuidam da merenda e da limpeza. Esse número é variável durante o ano, já que poucos são os professores com lotação efetiva nessa escola, o que gera uma rotatividade considerável de pessoal.

A Mirante é a única escola de ensino fundamental situada no bairro, sendo, portanto, uma referência muito significativa para os seus habitantes. Apesar dos problemas com as drogas no seu entorno, há uma convivência bastante pacífica da comunidade para com a escola e seus profissionais, podendo se observar uma relação de respeito, confiança e credibilidade, o que também se faz notar em conversas com algumas mães e com outros profissionais da unidade. 
O diretor, à época da pesquisa de campo, era conhecido por toda a comunidade e possuía uma boa aceitação das famílias, tendo já sido reeleito pela terceira vez. Para a comunidade, escolher o gestor que vai comandar a unidade é de fundamental importância, o que se pode notar pela votação expressiva durante as eleições. $\mathrm{O}$ índice de abstenções é muito pequeno. Os profissionais da escola observam que, apesar de considerar insuficiente o nível de participação dos pais na vida escolar do filho, quando há eleição para diretor esse segmento comparece em peso para votar.

Neste cenário da unidade de ensino, o diretor escolar possui uma vasta gama de responsabilidades. De modo especial, ele atua como um grande articulador nas questões inerentes ao funcionamento de uma escola, classificadas pelos profissionais da área como de natureza pedagógica, administrativa e financeira. Tendo em vista a natureza complexa da ação gerencial, em que se vivencia o imprevisível, conflitos e dilemas, tratou-se neste tópico de algumas nuances do exercício das funções administrativas no cotidiano da escola.

\subsection{Planejamento e Avaliação}

A dificuldade de realizar atividades sistematizadas por intermédio de um planejamento é uma realidade constante nas práticas do gestor escolar. Como lembra Esteban (2003, p. 202), "[...] a escola é a própria teoria do caos em realização. Tudo acontece ao mesmo tempo $e$, frequentemente, fora da hora que deveria acontecer". No cotidiano da Mirante, os fatos trazem sempre uma pitada de novidade, de surpresa e de inesperado.

Cada dia, o diretor programa os seus afazeres, mas esse planejamento é alterado por uma série de prioridades outras que surgem: uma demanda da Secretaria de Educação que exige uma pronta resposta; o atendimento de um pai que o aguarda; a intervenção em casos de "indisciplina"; a providência do conserto de um equipamento que quebrou, entre diversas outras situações que não estavam no "roteiro". Logo, observa-se que as atividades do diretor são atropeladas pelos imprevistos e o planejamento é algo que fica para o segundo plano. Enfim, no dia a dia da escola, tendo em vista a dinâmica dos acontecimentos, o diretor ocupa-se muito mais em ações do tipo "apagar incêndios" do que com ações planejadas.
Semanalmente, ocorrem na escola as reuniões administrativas, as quais são realizadas nos trinta minutos finais do expediente, ou seja, no intervalo entre o término das aulas e o encerramento da jornada - das $11 \mathrm{~h} 30 \mathrm{~min}$ às $12 \mathrm{~h}$ no turno matutino e das $17 \mathrm{~h} 30 \mathrm{~min}$ às $18 \mathrm{~h}$ no vespertino. As pautas mais frequentes são informes diversos, debates de questões cotidianas da instituição e tomadas de decisão em grupo.

Usualmente, os pontos de pauta das reuniões administrativas dos turnos matutino e vespertino são coincidentes, já que dizem respeito a assuntos gerais da escola. Um fato curioso que ocorre nessas reuniões é que o mesmo teor do que é dito pelo diretor, em cada turno, incita uma interpretação e uma reação diferente. E por conhecer o grupo e suas possíveis reações, a forma pela qual ele se expressa com os grupos também se diferencia. Isto porque no turno matutino, no qual frequentam alunos do $6^{\circ}$ ao $9^{\circ}$ anos, o grupo é de professores é formado por especialistas - aqueles que possuem graduação em áreas específica do conhecimento. Já no turno vespertino, onde estudam os alunos do $2^{\circ}$ ao $5^{\circ}$ anos, o grupo de docentes é formado por não especialistas - aqueles diplomados em pedagogia. Essas duas categorias profissionais, na visão do diretor, praticam distintas visões do cotidiano da educação e da escola.

O planejamento na escola é também praticado via conversas informais na sala dos professores e diversos outros encontros, em que surgem boas ideias, se formam parcerias e se compartilham saberes. Nesse sentido, embora os educadores se queixem de maiores espaços para discussão e planejamento, o que se observa é que eles acontecem, mesmo que os espaços oficiais não existam ou que eles sejam escassos. Então, como espaço construído, o planejamento é vivenciado em meio aos corredores da escola, no intervalo do café, nas lacunas entre uma aula e outra, ainda que sem frequência regular.

$\mathrm{Na}$ visão de um entrevistado, para além da destinação de maiores espaços para debate, é preciso recuperar a ideia de coletivo no grupo e a construção de uma efetiva proposta político-pedagógica da escola:

Pode até haver uma aglutinação de pessoas, mas para quê? Por quê? Com qual objetivo? [...] Se esse coletivo está desarranjado, distante, fragmentado, a cooperação não se torna palpável. Vocêtem pessoas reunidas e resultados não 
satisfatórios. [...] As coisas estão distantes de serem construídas solidamente. Eu sinto falta, por exemplo, da construção de uma cultura na escola. Uma cultura de educação, uma cultura de projetos, uma cultura do 'a que viemos' na escola, de qual o objetivo. Eu sinto muita falta disso. Não vejo um projeto político pedagógico eficiente. Existe, em toda escola, um projeto político pedagógico, mas você transformar esse projeto em realidade é complicado. Mais ainda, se você não tem propriedade dele, não compartilha dos valores desse projeto, dos objetivos desse projeto, ou se você nem conhece o projeto... Então a participação é vaga. Não se consegue construir muita coisa efetivamente na escola (Educador 1).

Já na avaliação de suas ações a escola utiliza o Plano de Ação, uma ferramenta destinada a definir atividades, projetos, metas e prioridades organizacionais, a partir do que é determinado pela Secretaria Municipal de Educação de Vitória - Seme. Em cada final de ano letivo, os profissionais reúnem-se para uma apreciar o período em curso, debatendo experiências positivas, falhas, novas demandas, desejos e apostas, e assim constroem um novo plano de trabalho para o ano vindouro. Essa avaliação envolve todos os educadores da Escola e, posteriormente, é apresentada à Seme. Conforme o relato do Educador 1 acima, observa-se que é grande o desafio lançado aos profissionais da escola em face das inúmeras questões que atravessam o cotidiano escolar.

Observa-se ainda que os sujeitos praticantes muitas vezes ao avaliarem o desempenho da escola, buscam justificar os insucessos por meio da "culpabilização". Ou seja, ora a culpa é da Seme, ora é do diretor, ou ainda do "Sistema", da sociedade, dos pais que não acompanham a vida escolar do filho, dentre tantos outros "bodes expiatórios". Segundo Lück (2007), tais queixas ou justificativas comumente utilizadas no dia-a-dia das escolas sugerem a carência de uma compreensão mais abrangente da organização escolar como uma instituição social, onde a experiência educacional se dá por meio de uma teia complexa de relações entre diversos componentes.

Portanto, seria ilusório acreditar que, se tais problemas não existissem, tudo funcionaria em perfeita ordem. Uma escola que apresenta uma boa participação dos pais não garante uma educação de qualidade. Ainda no entendimento de Lück (2007), o desenvolvimento de ações articuladas e mais consistentes passa, necessariamente, por uma ação conjunta de trabalho participativo em equipe, envolvendo toda a comunidade escolar, como prática mais efetiva em busca de melhoria de resultados a serem alcançados por uma unidade de ensino.

\subsection{Organização e Coordenação}

Na Mirante, o coordenador, cargo que até recentemente era denominado Assistente Técnico de Direção (ATD), é o profissional que atua diretamente na organização do expediente na unidade, assessorando a direção nesse quesito. Ele é encarregado de garantir o funcionamento da escola. Assim, zela pela limpeza; controla os recursos materiais de expediente e didáticos; coordena e organiza as entradas e saídas de alunos e os intervalos para recreios; coordena o preparo e a oferta da merenda. Enfim, é um profissional que atua em várias frentes de trabalho - o "braço direito do diretor" -, como costumam dizer na escola. Para garantir esse funcionamento, os coordenadores contam com a cooperação entre os diversos profissionais da escola, sempre zelando para "não deixar a peteca cair".

Na Mirante, o diretor tenta sempre garantir o oferecimento ao aluno de toda a carga horária a que ele tem direito por lei, mesmo que faltem recursos ou que, em determinado período, haja falta de educadores. Assim, o aluno só é dispensado quando se esgotam todas as possibilidades. São inventadas "mil maneiras" de se organizar, para garantir que esse aluno esteja na escola. Quando se ausenta algum professor, coordenadores, pedagogos ou outro docente assumem a regência da sala de aula, de forma a garantir o cumprimento do dia letivo.

Entretanto, essa prática de cooperação, que deveria ser uma eventualidade, ocorre muito frequentemente, o que leva a um desgaste dos profissionais. Em alguns casos, a licença médica e outros tipos de afastamento acabam tornando-se uma estratégia que os praticantes da escola utilizam para enfrentar as adversidades que encontram no seu cotidiano. Conforme relata uma servidora da Seme que atua diretamente com esses professores que solicitam afastamento, tal prática tem se tornado no magistério cada vez mais comum, dado o cenário atual da educação: 
O professor perdeu a qualidade de vida que lá no início dos anos 90 ele tinha. As pessoas tinham um vínculo ou no máximo dois, mas no mesmo município. Você saía no máximo de Jardim da Penha para São Pedro. As outras prefeituras não tinham atrativo. Então o professor perdeu muito a qualidade de vida e a licença médica acaba sendo uma válvula de escape. Se eu me aborreci com o meu diretor, eu tiro dez dias de licença médica. Se eu me aborreci com a mãe do meu aluno, eu tiro 30 dias de licença médica. Ontem eu tive um caso aqui. A professora se aborreceu com o aluno e tirou o resto da semana de licença médica. E como é que você substitui um professor por quatro dias, se um processo para contratar gira em torno de 40, 45 dias? (Educador 4).

Sendo assim, em determinadas situações, tais afastamentos podem ser considerados estratégias de resistência dos trabalhadores utilizadas no enfrentamento - "válvulas de escape" - de situações cotidianas. Sousa Filho (2002, p. 132) esclarece:

Do místico ao homem comum, driblar a autoridade, as verdades dogmáticas, os juízos aceitos, a rotinização da existência, funciona como uma espécie de "respiração" necessária para inscrever a novidade do dia na longa duração temporal, em todas as coisas reafirmadas, inscrever a vida na morte [...].

Em outras ocasiões, o problema não é a falta de pessoal, mas sim a falta de espaço físico. Quando este é fator limitador para a realização de algum projeto na escola, como atividades de reforço para os alunos, locais como a biblioteca, o refeitório e a sala das pedagogas são alternativas que os praticantes utilizam para torná-los possíveis. Vale lembrar ainda as parcerias realizadas com a comunidade local, o que é muito comum. Já houve situações em que a escola utilizou espaços da igreja e também uma sala cedida por um vereador para realização de projetos em um prédio próximo.

Apesar de possuir recursos limitados, a escola possui autonomia sobre o gasto das verbas a ela destinadas. Tais verbas são empregadas segundo desejo e prioridades da comunidade escolar, definidos em reuniões do Conselho de Escola. O diretor se esforça para realizar melhorias na escola e zela por sua con- servação, sendo esses atributos comumente destacados pelos seus sujeitos praticantes.

Em uma das reuniões do Conselho de Escola, foi possível conhecer um pouco da forma como os praticantes da escola "otimizam" os recursos a ela destinados. Na ocasião, foram apresentados três orçamentos para a realização de uma pequena reforma e instalação de equipamentos novos. O orçamento de menor valor, mesmo vencedor, ainda foi reduzido a um percentual aproximadamente de dez por cento. Isso porque, de posse dos valores ofertados na cotação, o diretor entrou em contato com o fornecedor vencedor e negociou uma redução no preço previamente apresentado, mesmo já tendo sido aprovado este mesmo valor pela Seme. Assim, observa-se que, mesmo na execução de um procedimento rígido, entra em cena a negociação que, neste caso, proporcionou uma economia para a unidade de ensino.

\subsection{Comando de Pessoas: dilemas e ambiguidades}

Quanto a seu modo de comandar, o gestor da Mirante delega tarefas, mas acompanha tudo de perto, para que quase nada escape ao seu controle. Essa prática se assemelha ao que Garcia (2009) denominou de "delegar de perto", isto é, um gestor que atribui a execução de tarefas a outros servidores, mas não a responsabilidade pelo que eles executam, o que se caracteriza como uma atitude centralizadora.

As relações de comando na prática do gestor escolar são atravessadas por ambiguidades. Isso porque, antes de ser gestor, ele também é parte do magistério. Em entrevista com uma gestora da Seme, esta revela que tal tipo de postura conflituosa é bastante comum e acaba por dificultar o exercício do cargo:

Porque o gestor ele é gestor, mas não consegue se desligar do lugar de categoria do magistério. A grande dificuldade dele é fazer esse equilíbrio, de tomar atitudes que deveriam ser de um gestor, mas ele ainda toma atitudes enquanto categoria de magistério. [...] Por exemplo, quando a gente encaminha do órgão central dizendo para os diretores que não é permitido tirar a carga horária do aluno para que o magistério vá para a Assembleia, que isso tem que ser reposto, ele não consegue enxergar que naquele momento ele é um gestor, que ele está defendendo ali 
também as crianças, o direito da criança, o direito dos pais e a carga horária desse aluno. Às vezes também aguenta o profissional, que não é um bom profissional, que está fazendo um certo mal à unidade de ensino, mas ele não faz o registro. Ele não quer se comprometer com o colega, porque ele diz que quando ele voltar, ele vai estar nesse lugar de novo. Então ele não consegue se desvincular, de quando é gestor e quando é magistério (Educador Seme).

Compartilhando essa visão, o diretor da Mirante admite que as pessoas não querem desagradar ou se indispor com os colegas. Assim, considera que enquanto muitos dos seus pares optam por manter uma "política da boa vizinhança", sendo cordial com todos e omitindo-se quando seria necessário cobrar do servidor, ele prefere "adotar uma postura firme", "tomar atitudes justas" e "trabalhar da maneira correta", isto é, saber dizer "não" quando julga necessário.

Todos os dias, logo que chega à escola, o diretor passa de sala em sala desejando um bom dia ou boa tarde. É neste momento que ele checa se está tudo em ordem, mas alguns professores sentem-se intimidados com esta conduta. Esse e outros tipos de ação de controle adotados pelo diretor são vistos por muitos que trabalham na escola como uma prática autoritária e opressora: "Ele age como se pagasse meu salário" (notas de campo, outubro de 2010), desabafa um profissional. Durante um dos momentos de entrevista, o diretor diz considerar as relações com os funcionários o ponto mais crítico da sua prática, como a dificuldade de lidar com as situações em que os servidores demonstram insatisfação com o trabalho, desmotivação ou até mesmo descompromisso.

Na sua percepção, o diretor da escola é visto pelos servidores como aquele que diz "não". Sendo assim, observou-se uma grande dificuldade do gestor de realizar o controle que lhe cabe, pois o que se espera do diretor é que ele atenda a todos os interesses dos funcionários e diga "sim" sempre, mantendo relações de cordialidade e pessoalidade no sentido em que Holanda (1997) e DaMatta (1990), respectivamente, as definem. Nesse sentido, ao ter de aplicar as sanções aos servidores ou mesmo exercer algum tipo de cobrança, o gestor vê-se mediante uma situação de conflito. Por exemplo: o corte do ponto de um funcionário que faltou ao trabalho sem o devido amparo legal implica que o gestor seja visto pelos demais servidores como um "ditador", ou como alguém "desumano", expressões utilizadas pelos próprios funcionários.

Pelo fato de o cargo de diretor ser eletivo, é mais comum que os diretores finjam não ver ou tentem encobrir tais atos para manter a "política da boa vizinhança", como dito anteriormente. Segundo Junquilho (2004), as estratégias de transigência ou da contemporização são muito comuns entre gestores na esfera pública como formas de evitar o conflito. Marra e Melo (2005) também constatam que a alternância de cargos, como ocorre em cargos eletivos, reforçam este tipo de prática, já que os gerentes temem sanções de seus pares quando já não mais no exercício do mandato.

Sendo assim, o diretor escolar procura sempre a busca por consensos ou por contemporizações para se legitimar no cargo de direção, mantendo-se na "corda bamba". É comum, por exemplo, como alternativa para tentar reduzir o índice de absenteísmos na escola, permitir a concessão de um número determinado de substituições. Quando o professor precisa faltar ao trabalho, para que não lhe seja cortado o ponto, ele pode enviar um substituto, desde que avise com antecedência. Nesse caso, o professor paga do próprio bolso a quem trabalha em seu lugar. Mas esse tipo de concessão não acontece à revelia. Existe uma cota que o professor pode utilizar dentro de um período de tempo.

Para o educador, pagar um substituto pode apresentar vantagens, uma vez que, em sua ficha funcional, não constará nenhum afastamento, falta ou licença médica, fato que o premia com cinco dias de licença no ano subsequente, segundo legislação dos servidores públicos do município de Vitória. Para o gestor também se configura como uma vantagem, uma vez que atende às necessidades do servidor, deixando-o satisfeito, e garante o cumprimento do dia letivo sem maiores desgastes para o calendário escolar.

Nesse sentido, observa-se que as normas e leis são importantes e imprescindíveis na organização da unidade escolar, porém, muitas vezes, elas também não dão conta da complexidade local, sendo necessários ajustes e "remendos" - tramas - que marcam a vida na escola. Assim, o diretor e a comunidade escolar vivenciam o cotidiano, criam práticas que permitem a reapropriação de espaços formalmente organizados normas e orientações gerais da Seme. Dito de outro modo, por meio de sua ação ou produção sociocultural 
(CERTEAU, 2009) o diretor escolar e demais sujeitos praticantes da Mirante re/criam "artes do fazer" gestão e tornam único, complexo e diferenciado o dia-a-dia das funções administrativas praticadas no seio daquela escola.

\section{Tessituras Finais}

Ao longo deste artigo, buscou-se tecer alguns fios sobre as diversas tramas que envolvem a gestão escolar, com base em "fragmentos" das práticas cotidianas que envolvem o agir de seu diretor e demais praticantes da escola Mirante. Essa tessitura complexa corrobora a gestão como uma prática social, conforme defendem Reed (1989); Schatzki $(2005,2006)$ e, em particular, como um fenômeno inerente a um cotidiano diverso e fragmentado, na concepção de relações sociais construídas pela ação humana, conforme escreve Certeau (2009).

Assim, na tentativa de superar as análises atomizadas acerca da gestão e ação gerencial, buscaram-se, a partir de Certeau (2009) e sua ênfase na vida cotidiana, subsídios para ampliar a compreensão do fazer gestão na escola pública. Os "fragmentos" aqui apresentados ilustrativos do cotidiano escolar apontaram a complexidade das "artes do fazer" gestão, marcada esta última, por uma rede de interseção de sujeitos e suas práticas. Isso reforça a gestão como um fenômeno/processo plural e ambíguo, no qual o diretor, responsável formal pela gestão da escola, é um praticante de importância no processo, mas não o único. Ou seja, ele gere a sua unidade, permeado por um emaranhado de práticas coletivas ou artimanhas de distintos sujeitos e suas relações sociais - "artes do fazer".

Logo, a análise da gestão deve ser dar não pela identificação da ação gerencial - de um sujeito diretor/ gestor - como realçaram estudos clássicos (MINTZBERG, 1973, 1990), mas sim por meio das práticas coletivas dos sujeitos que habitam o cotidiano da organização e que constroem processos de gestão, no qual o diretor é mais um praticante. Portanto, o planejamento, a organização, o controle e a avaliação da gestão, ou seja, o exercício das clássicas funções administrativas no cotidiano escolar, não obedece a uma sistematização prescrita, a priori, em manuais da Seme. Muito pelo contrário o fazer gestão é construído, no cotidiano e envolvem jogos de resistências e estratégias modificadoras que se entrelaçam ou ainda, são re/construídas nas/pelas práticas cotidianas.

É possível ainda a percepção de que a gestão escolar é tecida por meio de práticas sociais contingentes a diversos fatores espaço/temporais, instáveis, envoltas em conflitos e incertezas. As relações do gestor com os servidores - educadores e administrativos - são, em muitos casos, conflituosas pelo fato, por exemplo, de o diretor ter de administrar interesses antagônicos, como deslocar um funcionário de sua função ou sacrificar o horário de planejamento do professor para garantir a oferta da carga horária do aluno, sem se indispor com seus subordinados.

Os dilemas vividos pelo diretor escola são bem latentes em seu cotidiano. Há que se ressaltar que pelo fato de ser eleito, tem muitas dificuldades em lidar com seus pares, em dizer "não", sendo visto como autoritário ou adversário quando o faz. Pelo fato de ser um cargo provisório, com data para começar e terminar, o exercício de sua autoridade o coloca sempre na "corda bamba". Ou seja, tem que se equilibrar para efetivar ações de comando e controle, o que, por vezes, resulta em práticas contemporizadoras. Assim, seu cotidiano na prática da gestão é pautado por constantes negociações.

Diante dos apontamentos aqui apresentados, espera-se que este artigo venha colaborar com outros futuros que apresentem como foco o cotidiano das organizações, à luz de Certeau (2009). Nesse raciocínio, enseja-se que esta pesquisa suscite diálogos com interessado em estudos que tratem da gestão escolar como prática social. Dito de outro modo, há que se pensar gestão não como simples aplicação das funções administrativas, mas como um conjunto de práticas nas quais a gestão é resultante de "artes do fazer", a partir das quais as funções administrativas são inventadas e reinventadas cotidianamente. Ou, como diria Certeau (2008), pensar a gestão como resultante de um conjunto de práticas sociais, portanto, como um fenômeno "cultural plural". 


\section{Referências}

ALVES, N. Decifrando o pergaminho: o cotidiano das escolas nas lógicas das redes cotidianas. In: OLIVEIRA, I. B.; ALVES, N. (Org.). Pesquisa no/do cotidiano das escolas: sobre redes de saberes. Rio de Janeiro: DP\&A, 2002. p. 13-38.

ALVES, N; GARCIA, R. L (Org.). O sentido da escola. Rio de Janeiro: DP\&A, 2002.

BARNARD, C. The functions of the executive.

Cambridge: Harvard University Press, 1938.

BASTOS, J. (Org.). Gestão democrática. 4. ed. Rio de Janeiro: DP\&A: SEPE, 2005.

BRASIL. Constituição da República Federativa do

Brasil, 1988. Brasília: Senado Federal, Centro Gráfico, 1988.

BRASIL. Congresso Nacional. Lei n. 9.394, de 20 de dezembro de 1996. Estabelece as diretrizes e bases da educação nacional. Disponível em: < http://www.planalto. gov.br/ccivil_03/leis/19394.htm>. Acesso em: 14 jun. 2012.

CARLSON, S. Executive behavior: a study of the work load and the working methods of managing directors. Stockholm: Strömbergs, 1951.

CAVEDON, N. Antropologia para administradores. Porto Alegre: UFRGS, 2003.

CERTEAU, M. A invenção do cotidiano: 1 . as artes de fazer. 16. ed. Petrópolis: Vozes, 2009.

A cultura no plural. 5. ed. Campinas: Papirus, 2008.

COLLINS, O. F.; MOORE, D. G. The organization makers. New York: Appleton, 1970.

CYERT, R. M.; MARCH, J. G. A behavioral theory of the firm. 2. ed. Oxford: Blackwell, 1996.

DALTON, M. Men who manage. New York:Wiley, 1959.

DaMATTA, R. Carnavais, malandros e heróis: para uma sociologia do dilema brasileiro. 5. ed. Rio de Janeiro: Guanabara Koogan, 1990.
DENIS, J.; LANGLEY, A.; ROULEAU, L. Strategizing in pluralistic contexts: rethinking theorical frames. Human relations, London, v. 60, n. 1, p. 179-215, 2007.

DORA, R. Grasmci e o debate sobre a escola pública no Brasil. Cadernos Cedes, Campinas, v. 26, n. 70, p. 329 352, 2006.

DRABACH, N.; MOUSQUER, M. Dos primeiros escritos sobre administração escolar no Brasil aos escritos sobre gestão escolar. Currículo sem Fronteiras, Pelotas, v. 9, n. 2, p. 258-285, jul./dez. 2009.

DURAN, M. Maneiras de pensar o cotidiano com Michel de Certeau. Diálogo Educ., Curitiba, v. 7, n. 22, p. 115128, set.-dez., 2007.

ESTEBAN, M. Dilemas para uma pesquisadora com o cotidiano. In: GARCIA, R. (Org.). Método: pesquisa com o cotidiano. Rio de Janeiro: DP\&A, 2003. p. 199-212.

ÉSTHER, A. B.; MELO, M. C. O. L. Ambiguidades e dilemas do trabalho gerencial. REAd - Revista Eletrônica de Administração, Porto Alegre, v. 12, n. 50, p. 1-23, 2006.

FAYOL, H. Administração industrial e geral. 8. ed. São Paulo: Atlas, 1970.

FERRAÇO, C. E. Eu, caçador de mim. In: GARCIA, R. L. (Org.) Método: pesquisa com o cotidiano. Rio de Janeiro: DP\&A, 2003. p. 157-175

Pesquisa com o cotidiano. Educ. Soc., Campinas, v. 28, n. 98, p. 73-95, jan.-abr. 2007.

GALVÃO, V.; SILVA, A. B.; SILVA, W. R. O desenvolvimento de competências gerenciais nas escolas públicas estaduais. Educação e Pesquisa. São Paulo, 2011. (No prelo). Disponível em: < http:// www.scielo.br/scielo.php?script =sci_pdf\&pid $=$ S1517$97022011005000002 \& \operatorname{lng}=e n \& n r m=$ iso\&tlng $=p t>$. Acesso em: 13 out. 2011.

GARCIA, R. Tentando compreender a complexidade do cotidiano. In: GARCIA, R. L. (Org.) Método: pesquisa com o cotidiano. Rio de Janeiro: DP\&A, 2003. p. 9-16 


\section{GARCIA, E. UNIVERSIDADE FEDERAL DO ESPÍRITO} SANTO Centro de Ciências Jurídicas e Econômicas.

Ação gerencial no setor público: o caso CESAN. 2009. 194 f. Dissertação (Mestrado) - Universidade Federal do Espírito Santo, Centro de Ciências Jurídicas e Econômicas.

GEERTZ, C. Interpretação das culturas. Rio de Janeiro: Guanabara Koogan, 1989.

HELLER, A. O cotidiano e a história. 8. ed. São Paulo: Paz e Terra, 2008.

HOLANDA, S. Raízes do Brasil. São Paulo: Companhia das Letras, 1997.

HOMANS, G. The human group. New York: Harcourt Brace Jovanovich, 1950.

JUNQUILHO, G. Nem "burocrata" nem novo "gerente": o caboclo e os desafios do Plano Diretor de Reforma do Estado no Brasil do real. Revista de Administração Pública, Rio de Janiro, v. 38, n. 1, p. 137-156, jan.-fev. 2004.

KOTTER, J. P. The general managers. New York:Amacom, 1982.

\section{LAROSSA, J. Linguagem e educação depois de}

Babel. Belo Horizonte: Autêntica, 2004.

\section{LÜCK, H. A gestão participativa na escola.}

Petrópolis: Vozes, 2006.

Gestão educacional: uma questão paradigmática. 3. ed. Petrópolis: Vozes, 2007.

MARRA, A. V.; MELO, M. C. de O. L. A prática social de gerentes universitários em uma instituição pública.

Revista de Administração Contemporânea, Curitiba, v. 9, n. 3, p. 9-31, jul.-set. 2005.

MARCH, J. G.; SIMON, H. A. Organizations. New York: Wiley, 1958.

MINTZBERG, $\mathrm{H}$. The nature of managerial work. New York: Harper Row, 1973.

. The manager's job: folklore and fact. Harvard

Business Review, Massachusetts, p. 163-176, Mar.-Apr. 1990.
MORIN, E. Ciência com consciência. Rio de Janeiro: Bertrand Brasil, 1996.

OLIVEIRA, I. B. Certeau e as artes de fazer: as noções de uso, tática e trajetória na pesquisa em educação. In: OLIVEIRA, I. B.; ALVES, N. (Org.). Pesquisa no/do cotidiano das escolas: sobre redes de saberes. Rio de Janeiro: DP\&A, 2002. p. 39-54.

Estudos do cotidiano, pesquisa em educação $e$ vida cotidiana: o desafio da coerência. ETD - Educação Temática Digital, Campinas, v. 9, n. esp., p. 162-184, out. 2008.

PAIVA, K. C. M. de et al. Função Gerencial em Shopping Center: Ação, Devoção e Desilusão. In: I Encontro Nacional de Gestão de Pessoas e Relações de Trabalho, 1. 2007, Natal. Anais... Natal: ANPAD, 2007.

PARO, V. A educação, a política e a administração: reflexões sobre a prática do diretor de escola. Educação e Pesquisa, São Paulo, v. 36, n. 3, p. 763-778, sept./dez. 2010.

REED, M. Management as a social practice. Journal of Management Studies, Oxford, v. 21, n. 3, p. 273-285, 1984.

The sociology of management. London: Harvester Wheatsheaf, 1989.

ROCHA, H. C. A formação econômica do Espírito Santo e sua lógica empresarial. In: VASCONCELOS, J. G. M.; DAVEL, E. P. B. (Org.) Inovações organizacionais e relações de trabalho: ensaios sobre o Espírito Santo. Vitória: EDUFES, 1998. p. 33-75.

ROCKWELL, E.; EZPELETA, J. A escola: relato de um processo inacabado de construção. Currículo sem Fronteiras, Pelotas, v. 7, n. 2, p. 131-147, jul./dez. 2007.

SANTOS, L.; ALCADIPANI, R. Por uma epistemologia das práticas administrativas: a contribuição de Theodore Schatzki. In: XXXIV Encontro da Associação Nacional de Programas de Pós-Graduação em Administração, 34. 2010, Rio de Janeiro, Anais... Rio de Janeiro: ANPAD, 2010.

SARMENTO, M. J. Lógicas de Acção nas Escolas. Lisboa: Instituto de Inovação Educacional, 2000. 
SCHATZKI, T. The sites of organizations. Organization

Studies, London, v. 26, n. 3, p. 465-484, 2005.

. On organizations as they happen. Organization

Studies, London, v. 27, n. 12, p. 1.863-1.873, 2006.

SIMON, H. Comportamento administrativo: estudo

dos processos decisórios nas organizações administrativas.

2. ed. Rio de janeiro: FGV, 1970.

SOUSA FILHO, A. Michel de Certeau: Fundamentos de uma sociologia do cotidiano. Sociabilidades, São Paulo, v. 2, 2002. p. 129-134.

SOUZA, A.; GOUVEIA, A. Diretores de escolas públicas: aspectos do trabalho docente. Educar em Revista, Curitiba, n. esp. 1, p. 173-190, 2010.

STEWART, R. Contrasts in management. Maidenhead: McGraw-Hill, 1976.

The reality of management. 3. ed. Oxford:

Butterworth Heinemann, 1997.

TAYLOR, F. Princípios de administração científica.

4. ed. São Paulo: Atlas, 1960.

WHITLEY, R. On the Nature of Managerial Tasks: their distinguishing characteristics and organization. Journal of Management Studies, Oxford, v. 26, n. 3, p. 209224, 1989. 